\title{
ANALISIS PARTISIPASI MASYARAKAT DALAM MUSYAWARAH PERENCANAAN PEMBANGUNAN DI DESA DONGI KECAMATAN PITU RIAWA KABUPATEN SIDENRENG RAPPANG
}

\author{
MUH REZKI \\ Prodi administrasi publik. Fakultas ilmu sosial dan ilmu politik \\ Universitas Muhammadiyah Sidenreng Rappang
}

Muhreski43182021@gmail.com

\begin{abstract}
ABSTRAK
Tujuan penelitian ini untuk mengetahui partisipasi masyarkat dalam proses perencanaan pembangunan di desa dongi kecamatan pitu riawa kabupaten sidenreng rapang. Peneletian ini menggunakan metode deskriktif kuantitatif.

Kata kunci; Musrenbang, partipasi masyarakat.
\end{abstract}

\section{PENDAHULUAN}

A. LATAR BELAKANG

Peran serta masyarakat dalam pembangunan sudah ada sejak UU 1945 diberlakukan secara konstutisional dan telah memiliki acuan yang jelas dan merupakan kewajiaban bagi setiap yang terlibat dalam pengelolaan sumber daya di indonesia. namun peran serta partisipasi masyarakat dalam pembangunan di era reformasi masih menunjukkan kecenderungan yang berjalan dengan sempurna. Peran masyarakat sejak awal hingga kini belum mendapatkan posisi yang tepat dalam ikut berpartisipasi dalam perencanaan pembangunan dalam pembangunan di desa 
sangat dibutuhkan kerjasama yang baik antara pihak masyrakat dengan aparat pemerintahan sehingga masyarakat yang adil dan makmur dapat tercapai sebagaimana cita cita bangsa yang tertuang dalam uud 1945. Dalam perencanaan program pembangunan nasional ini tidak lepas dari perencanaan pembangunan masyarakat desa. karena desa merupakan bagian dari landasan negara ri yang dapat diukur dalam kancah pembangunan nasional,serta kaitannya dengan kondisi kondisi sosial sebagian masyarakat yang masih terbelakang tentu ini menjadi tantangan untuk meningkatkan kesejahteraaan masyarakat.

Namun jika kita melihat kebelakang , mulai dari tahap perencanaan pembangunan yang menggukan pola berjenjang dari bawah ke atas bottom up ternyata tidak terlalu menjanjikan bahwa aspirasi warga akan didengar. Begitupulah dalam pelaksanaan pembangunan yang menggunakan tenaga ahli ini menunjukan bahwa masyarakat tidak terlalu berkontribusi terhadap pembangunan desa, peran masyarakat hanya terlihat pada saat tahap perencanaan saja dan pada tahap tersebutpun masih banyak langkah langkah yang belum terlaksana secara sempurna. Sehinggan masyarakat yang secara langsung merasakan manfaat kurang dilibatkan karena dari awal partisipasi masayrakat tidak terlalu banyak dan di lembaga tingkat rendahpun misalnya desa atau kelurahan kadang masyarakat tidak digubris. Dan pada tahap perencanaan mulai dari musrenbang desa kelurahan Cuma mencatat daftar daftar kebutuhan masyarakat ketimbang sebagai rencana parsitipatif. Proses inilah yang menjadikan proses birokrasi menjadi panjang dan lama, sehingga masyrakat tidak mendapat kepastian kapan keinginannya akan terwujud.

Partisipasi masyarakat berarti keterlibatan masyarakat secara fisik dan menggunakan segala kemampuan yang dimiliki dan bernisiatif dalam segala kegiatan yang dilaksanakan serta ikut bertanggung jawab serta mendukung segala tujuan yang telah direncanakan Partisipasi masyarakat dalam pelaksanaan pembangunan berjalan dengan baik, masyarakat tidak lagi menjadi obyek pembangunan tetapi telah menjadi subyek pembangunan. Dengan maksud agar partisipasi masyarakat dalam pelaksanaan pembangunan dilihat tidak hanya dari antusiasme orang yang menghadiri Musrenbang, tetapi juga dari cara pemerintah telah memperhatikan kepentingan mereka, juga sebagai proses keterlibatan mereka dari perencanaan untuk pelaksanaan proyek pembangunan. 


\section{TINJUAUAN PUSTAKA}

\section{PENGERTIAN PARTISIPASI}

partisipasi masyarakat merupakan keterlibatan atau keikutsertaan seseorang masyarakat dalam proses interaksi sosial, pengidentifikasian masalah dan potensi yang ada di masyarakat dalam situasi tertentu, baik dalam pengambilan keputusan (solusi) menangani masalah, pelaksanaan upaya mengatasi masalah, dan proses keterlibatan masyarakat di dalam mengevaluasi perubahan yang terjadi. Menurut (Mustanir \& Razak, 2017).

beberapa faktor yang mempengaruhi partisipasi masyarakat dalam musyawarah rencana pembangunan (musrenbang) antara lain adalah faktor sosial budaya yang mencakup; norma, nilai kepercayaan, dan sikap. Bukan sesuatu hal yang mudah untuk menerapkan partisipasi terutama pada suatu lingkungan masyarakat tertentu dikarenakan faktor-faktor tersebut. Sehingga prinsip-prinsip partisipasi harus memperhatikan kebersamaan, tumbuh dari bawah (bottom up) dan kepercayaan dan keterbukaan(Mustanir \& Razak, 2017).

partisipasi adalah turut sertanya masyarakat pada proses mengidentifikasi potensi dan masalah, ikut sertanya masyarakat dalam pengambilan keputusan, pelaksanaan keputusan, serta keterlibatan dalam proses evaluasi kegiatan. Partisipasi masyarakat menekankan pada "partisipasi" warga secara langsung di lembaga dan dalam proses pemerintahan.(Adam Latif1, Irwan2, 2019)

Partisipasi masyarakat adalah pemberdayaan masyarakat, peran sertanya dalam kegiatan penyusunan perencanaan implementasi program/proyek pembangunan, dan merupakan aktualisasi dan kesediaan dan kemauan masyarakat untuk berkorban dan berkontribusi terhadap implementasi Program Pembangunan.(Mustanir \& Abadi, 2017)

Uceng, Ali, Mustanir, \& Nirmawati, 2019; Uceng, Erfina, Mustanir, \& Sukri, 2919) mengatakan bahwa konsep partisipasi juga meliputi : Partisipasi mengenai hak politik, termasuk didalam pengambilam kebijakan publik, dilakukan secara sistemik, sebagai instrumen yang mendorong tata pemerintahan yang baik, serta dapat meningkatkan kepercayaan masyarakat terhadap penyelenggaraan pemerintahan(Adam Latif1, Irwan2, 2019)

Partisipasi masyarakat menurut Isbandi (2007: 27) adalah keikutsertaan masyarakat dalam proses pengidentifikasian masalah dan potensi yang ada di masyarakat, pemilihan dan pengambilan keputusan tentang alternatif solusi untuk menangani masalah, pelaksanaan upaya mengatasi masalah, dan keterlibatan masyarakat dalam proses mengevaluasi perubahan yang terjadi.(Mustanir, 2016)

partisipasi masyarakat merupakan keterlibatan atau keikutsertaan seseorang masyarakat dalam proses interaksi sosial, pengidentifikasian masalah dan potensi yang ada di masyarakat dalam situasi tertentu, baik dalam pengambilan keputusan (solusi) menangani masalah, pelaksanaan upaya mengatasi masalah, dan proses keterlibatan masyarakat di dalam mengevaluasi perubahan yang terjadi. Menurut(Mustanir \& Razak, 2017) 
Partisipasi sepadan dengan arti peranserta, ikutserta, keterlibatan, atau proses belajar bersama saling memahami, menganalisis, merencanakan dan melakukan tindakan oleh sejumlah anggota masyarakat. Penggalangan partisipasi itu dilandasi adanya pengertian bersama dan adanya pengertian tersebut adalah karena diantara orang-orang itu saling berkomunikasi dan berinteraksi sesamanya. Dalam menggalang peran serta semua pihak itu diperlukan (1) terciptanya suasana yang bebas atau demokratis dan (2) terbinanya kebersamaan. Selanjutnya dinyatakan bahwa, partisipasi masyarakat dalam pembangunan adalah sebagai ikut sertanya masyarakat dalam pembangunan, ikut dalam kegiatan-kegiatan pembangunan, dan ikut serta memanfaatkan dan menikmati hasil-hasil pembangunan.(Mustanir \& Abadi, 2017)

Selanjutnya menurut Adisasmita (2006:41) Partisipasi Masyarakat adalah pemberdayaan masyarakat, peran sertanya dalam kegiatan penyusunan perencanaan implementasi program/proyek pembangunan, dan merupakan aktualisasi dan kesediaan dan kemauan masyarakat untuk berkorban dan berkontribusi terhadap implementasi Program Pembangunan. Dengan demikian partisipasi masyarakat merupakan proses ketika warga, sebagai individu maupun kelompok sosial dan warga, mengambil peran, serta ikut mempengaruhi proses perencanaan, pelaksanaan dan pemantauan kebijakan-kebijakan yang langsung mempengaruhi kehidupan mereka. (Mustanir \& Yasin, 2018)

\section{MUSYAWARAH RENCANA PEMBANGUNAN DESA}

Musrenbang merupakan forum perencanaan (program) yang diselenggarakan oleh lembaga publik yaitu pemerintah kelurahan bekerjasama dengan warga dan para pemangku kepentingan lainnya. Musrenbang bermakna, akan mampu membangun kesepahaman tentang kepentingan dan kamajuan kelurahan dengan cara memotret potensi dan sumbersumber pembangunan yang tersedia baik dari dalam maupun dari luar daerah. Musrenbang(Mustanir \& Abadi, 2017)

Musrenbang adalah Perencanaan Pembangunan Bersama Masyarakat adalah merupakan panduan atau model pembangunan kelurahan yang menitikberatkan pada peran serta masyarakat dalam keseluruhan proses pembangunan 16 . Pendekatan ini dilandasi oleh nilai -nilai dan semangat gotong-royong yang telah mengakar dalam budaya masyarakat Indonesia. Gotong-royong bertumpu pada keyakinan bahwa setiap warga masyarakat memiliki hak untuk memutuskan dan merencanakan apa yang terbaik bagi diri dan lingkungan serta cara terbaik dalam upaya mewujudkannya. Secara garis besar musrenbang mengandung pengertian sebagai berikut:

1. Perencanaan sebagai serangkaian kegiatan analisis mulai dari indentifikasi kebutuhan masyarakat hingga penetapan program pembangunan.

2. Perencanaan pembangunan lingkungan, semua program peningkatan kesejahteraan, 
ketenteraman, kemakmuran dan perdamaian masyarakat di lingkungan pemukiman dari tingkat RT/RW, dusun dan kelurahan.

3. Perencanaan pembangunan bertumpu pada masalah, kebutuhan, aspirasi dan sumber daya masyarakat setempat.

4. Wujud nyata peran serta masyarakat dalam perencanaan pembangunan. Musrenbang berfungsi sebagai proses negosiasi, rekonsiliasi dan harmonisasi

5. perbedaan antara pemerintah dan pemangku kepentingan non pemerintah, sekaligus mencapai consensus bersama mengenai prioritas kegiatan pembangunan anggaran.

6. Musrenbang adalah forum-forum multi-pihak terbuka yang (Mustanir \& Abadi, 2017)

secara bersama mengidentifikasi dan menentukan prioritas kebijakan pembangunan masyarakat. Musyawarah perencanaan pembangunan (musrenbang) Kecamatan adalah forum musyawarah tahunan para pemangku kepentingan (stakeholders) Kecamatan untuk menyepakati rencana kerja Kecamatan tahun anggaran berikutnya (tim kerja buku panduan penyelenggaraan Musrenbang, (Ahmad Mustanir1), Muhammad Rohady Ramadhan2), $M$ Rais Rahmat Razak3), Lukman4), 2019)

S. Pradja (26: 2014) dalam menjelaskan pemimpin dan kepemimpinan, ada beberapa hal yang perlu di perhatikan, di antaranya: pertama, kekuasaan dan kewenangan, yaitu kemampuan untuk bertindak bagi seorang pemimpin untuk menggerakkan bawahannya agar mengikuti kehendaknya dalam mencapai tujuan yang telah di tentukan sebelumnya. Kedua, kewibawaan, yaitu berbagai keunggulan yang dimiliki seorang pemimpin, sehingga membedakan dengan yang di pimpinnya, dan dengan keunggulan tersebut, orang lain patuh dan bersedia melakukan kegiatan-kegiatan yang di

kehendakinya. Ketiga, kemampuan, yaitu keseluruhan daya, baik berupa keterampilan sosial maupun keterampilan teknis yang melebihi orang lain.(Mustanir \& Jaya, 2016)

Pengertian Kepemimpinan yaitu bentuk dominasi yang didasari atas kemampuan pribadi yang sanggup mendorong atau mengajak orang lain untuk berbuat sesuatu yang berdasarkan penerimaan oleh kelompoknya, dan memiliki keahlian khusus yang tepat bagi situasi yang khusus. adalah kemampuan seseorang untuk mempengaruhi orang lain dalam hal ini para bawahannya sedemikian rupa sehingga orang lain itu mau melakukan kehendak pemimpin meskipun secara pribadi hal itu mungkin tidak disenanginya. Kepemimpinan tidak hanya berarti pemimpin terhadap manusia, tetapi juga pemimpin terhadap perubahan.

Seorang pemimpin tidak harus memengaruhi bawahan tetapi harus juga sebagai sumber inspirasi dan motivasi bagi bawahannya. Oleh karena itu definisi dan penafsiran kepemimpinan semakin beragam dalam perkembangannya. (Irwan1), Adam Latif2), Sofyan3), Ahmad Mustanir 4), 2019)

(Mustanir and Abadi 2017) mendefinisikan perencanaan pembangunan suatu kumpulan kebijaksanaan dan program pembangunan untuk merangsang masyarakat dan swasta untuk menggunakan sumber daya yang tersedia secara lebih produktif. Perencanaan(Ahmad Mustanir1, Fitriani S1, Khaeriyah Adri1, Andi Ayu Nurnawati1, 2020) 
Perencanaan pembangunan merupakan suatu tahapan awal dalam proses pembangunan. Sebagai tahapan awal, perencanaan pembangunan akan menjadi bahan/pedoman/acuan dasar bagi pelaksanaan kegiatan pembangunan (Riyadi \& Bratakusumah, 2004) (Mustanir and Rusdi. Muhammad 2019).(Ahmad Mustanir1, Fitriani S1, Khaeriyah Adri1, Andi Ayu Nurnawati1, 2020)

\section{PEMBAHASAN}

Masyarakat mempunyai hak dan kewajiban yang sama dalam upaya mendukung suksesnya pembangunan di daerahnya. Sebagai warga negara yang aktif masyarakat harus selalu tanggap dengan segala perencanaan kebijakan yang dikeluarkan oleh pemerintah.

Masyarakat mesti terlibat dan dilibatkan dalam perumusan kebijakan publik, karena idealnya kebijakan dalam suatu negara demokrasi merupakan aspirasi dari rakyat oleh rakyat dan untuk rakyat.(Muhammad Ikbal, 2019)

Salah satu kegiatan perencanaan pembangunan yang biasanya dilaksanakan adalah musyawarah perencanaan pembangunan, yaitu forum-forum multi-pihak terbuka yang secara bersama mengidentifikasi dan menentukan prioritas kebijakan pembangunan masyarakat.(Ahmad Mustanir1), Akhmad Yasin2), Irwan3), 2018)

Peran masyarakat dalam upaya berpartisipasi dalam perencanaan pembangunan di desa dongi juga didukung dari oleh pemerintah setempat melibatkan persetujuan masyarakat dalam perencanaan pembangunan. Ini bisa menjadi faktor pembangunan akan tepat sasaran dan terlaksana dengan baik dan hasilnya akan bermamfaat dan diharapkan bisa memenuhi kebutuhan masyarakat ini bisa terjadi karena adanya koordinasi yang baik antara pemerintah dengan masyarakat.

Dengan adanya kecenderungan bahwa usulan yang diajukan dalam Musrenbang Kecamatan yang sesungguhnya masih jauh dari harapan. Fenomena ini dapat dilihat dari kehadiran masyarakat dalam musrenbang di desa, kegiatan Musrenbang dihadiri oleh masyarakat desa dan Pemerintah Desa setempat. Sebelum dilaksanakan Musrenbang, masyarakat desa menyerahkan daftar identifikasi kebutuhan mereka ke Kantor kepala Desa sebelum penyelenggaraan musrenbang, pada tahap musrenbang, aparat desa membacakan daftar identifikasi kebutuhan dari masyarakat desa, namun tidak mendiskusikan kebutuhan mana yang dijadikan prioritas yang akan diusulakan pada musrenbang tahapan selanjutnya.

Pelaksanaan Musrenbang diarahkan untuk menjadi wadah bagi partisipasi masyarakat miskin dan pemberdayaan perempuan, sehingga hasil proses perencanaan yang dilakukan dapat lebih berpihak kepada mereka. Meskipun selama ini pelaksanaan Musrenbang diwarnai dengan suasana dialogis yang sangat kental akan tetapi kondisi tersebut belum bersahabat untuk mengakomodir bahkan memberikan kesempatan bagi masyarakat miskin maupun kaum perempuan untuk menyampaikan uneg uneg, pendapat, saran atau keinginan mereka untuk memperbaiki keterperukan ekonomi yang mereka alami, musrenbang masih menjadi domain bagi para elit desa untuk 
menyampaikan proyek-proyek yang sarat dengan kepentingan. (Muhammad Ikbal, 2019)

\section{KESIMPULAN}

Berdasarkan hasil penelitian da pembahasan maka ditarik kesimpulan pemerintah desa dongi sudah melibatkan masyarakat dalam proses perencanaan pembangunan dan meminta persetujuan masyarakat ini diharapkan tentunya bahwa pembangunan akan tepat sasaran dan berguna masyarakat.

\section{DAFTAR PUSTAKA}

Adam Latif1, Irwan2, A. M. (2019). Analisis Kepemimpinan Terhadap Optimalisasi Masyarakat Pada Perencanaan Pembangunan Di Enrekang. Journal Homepage, 3(december), 1-20.

Ahmad Mustanir1, Fitriani S1, Khaeriyah Adri1, Andi Ayu Nurnawati1, G. G. (2020). Sinergitas Peran Pemerintah Desa dan Partisipasi Masyarakat Terhadap Perencanaan Pembangunan di Kabupaten Sidenreng Rappang. Jurnal of Government Science, 1(2), 84-108.

Ahmad Mustanir1), Akhmad Yasin2), Irwan3), M. R. (2018). POTRET IRISAN BUMI DESA TONRONG RIJANG DALAM TRANSECT PADA PERENCANAAN PEMBANGUNAN PARTISIPATIF PORTRAIT. Jurnal Moderat, 4(4), 1-14.

Ahmad Mustanir1), Muhammad Rohady Ramadhan2), M Rais Rahmat Razak3), Lukman4), S. T. (2019). Peranan Camat dan Komunikasi Pemerintahan terhadap Perencanaan Pembangunan di Kecamatan Malua Kabupaten Enrekang. IImiah Clean Goverentment, 2(Juni), 94-114. https://doi.org/10.31219/osf.io/8jbkx

Irwan1), Adam Latif2), Sofyan3), Ahmad Mustanir 4), F. 5). (2019). GAYA KEPEMIMPINAN, KINERJA APARATUR SIPIL NEGARA DAN PARTISIPASI MASYARAKAT TERHADAP PEMBANGUNAN DI KECAMATAN KULO KABUPATEN SIDENRENG RAPPANG. Jurnal Moderat, 5(1), 32-43.

Muhammad Ikbal, 2)Abdul Jabbar A. (2019). Partisipasi masyarakat dalam perencanaan pembangunan desa dongi kecamatan pitu riawa kabupaten sidenreng rappang 1 ). Jurnal Wedana, V(1), 581-588.

Mustanir, A. (2016). Prosiding Seminar Nasional Reformasi dan Inovasi Tata Kelola Pemerintahan. Prosiding Seminar Nasional Dan Pertemuan APSIPI "Reformasi Dan Inovasi Tata Kelola Pemerintahan,"289-307.

Mustanir, A., \& Abadi, P. (2017). Partisipasi Masyarakat Dalam Musyawarah Rencana Pembangunan Di Kelurahan Kanyuara Kecamatan Watang Sidenreng Kabupaten Sidenreng Rappang. Jurnal Politik Profetik, 5(2), 247-261. http://journal.uinalauddin.ac.id/index.php/jpp/article/viewFile/4347/3986\%0Ahttp://journal.uinalauddin.ac.id/index.php/jpp/issue/view/636

Mustanir, A., \& Jaya, I. (2016). Pengaruh Kepemimpinan Dan Budaya Politik Terhadap Perilaku Pemilih Towani Tolotang Di Kecamatan Maritengngae Kabupaten Sidenreng Rappang. Jurnal Politik Profetik, 4(1), 84-97. http://journal.uin- 
alauddin.ac.id/index.php/jpp/article/view/2741\#\%0Ahttp://journal.uinalauddin.ac.id/index.php/jpp/issue/view/430

Mustanir, A., \& Razak, M. R. R. (2017). Nilai Sosial Budaya Pada Partisipasi Masyarakat Etnik Towani Tolotang Dalam Musyawarah Rencana Pembangunan. Prosiding Konferensi Nasional Ke-6 Asosiasi Program Pascasarjana Perguruan Tinggi Muhammadiyah Aisyiyah (APPPTMA), September, 1-7. http://asosiasipascaptm.or.id/index.php/publikasi/prosiding-konferensi-nasionalappptma-ke-6

Mustanir, A., \& Yasin, A. (2018). Transect Pada Perencanaan Pembangunan Partisipatif. 8(2), 21-31. 